\title{
MONTAGEM E EFEITO FILME NA NARRATIVA FOTOGRÁFICA "A IRA DE DEUS", DE ALFREDO NICOLAIEWSKY ${ }^{1}$
}

\author{
MONTAGE AND FILM EFFECT IN THE PHOTOGRAPHIC NARRATIVE "THE \\ GOD'S IRE”, BY ALFREDO NICOLAIEWSKY
}

Elaine Tedesco

PPGAV/ UFRGS

Resumo: O presente texto apresenta uma leitura da obra "A Ira de Deus", de Alfredo Nicolaiewsky. A partir de depoimentos do artista e dos conceitos "efeito filme", de Philippe Dubois; "mestiçagem", de Icleia Cattani; e "montagem dialética e montagem simbólica", de Jacques Rancière, procurou-se entender como a montagem com justaposição de fotografias, realizada a partir da apropriação de cenas de filmes disponíveis na internet, resulta em uma narrativa aberta.

Palabras-chave: Alfredo Nicolaiewsky. Filme. Fotografia. Montagem. Narrativa.

Abstract: This paper aims to understand The God's Ire, by Alfredo Nicolaiewsky. Based on interviews with the artist and on the concepts: "film effect", by Philippe Dubois; "miscegenation", by Icleia Cattani; and "dialectical montage and symbolic montage" by Jacques Rancière, we analyze how the "tableau" using photographic juxtaposition, made with the appropriation of movie stills, available on the Internet, results in a open narrative.

Keywords: Alfredo Nicolaiewsky. Movie. Montage. Narrative. Photography.

1 Esta é uma versão expandida do artigo publicado na Revista Estúdio, artistas sobre outras obras. ISSN 1647-6158 e-ISSN 16477316. 9, (22), abril-junho, 2018. 28-36. 
Figura 1 - Alfredo Nicolaiewsky, Sem título, 1983 | lápis de cor e aquarela sobre papel, $70 \times 98 \mathrm{~cm}$, Coleção do artista.

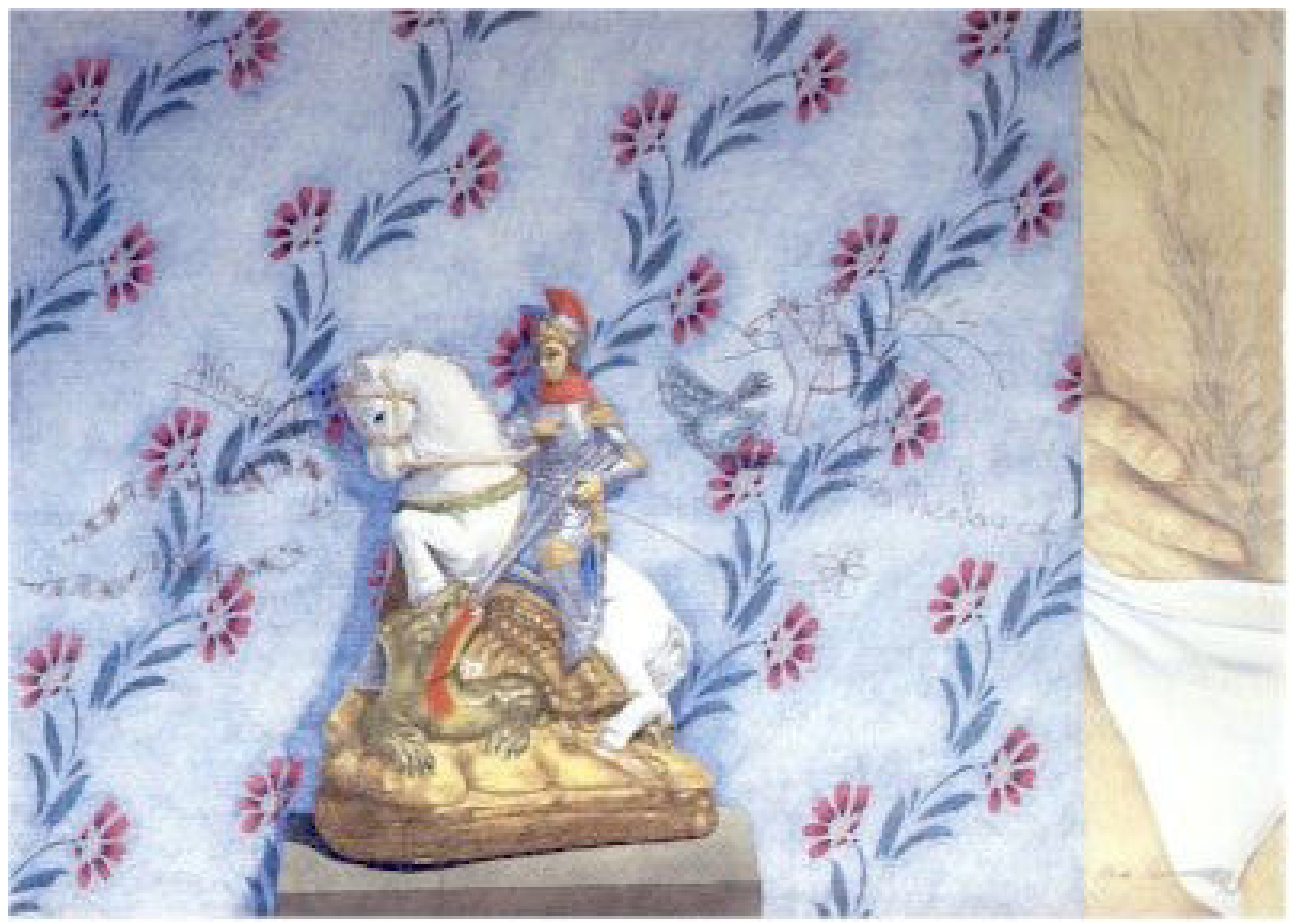

Alfredo Nicolaiewsky nasceu em 1952, graduou-se em arquitetura e cursou mestrado e doutorado em Artes Visuais, na área de Poéticas Visuais, na Universidade Federal do Rio Grande do Sul, onde, também, foi diretor do Instituto de Artes por oito anos.

No início de sua carreira, sua obra constituiuse tendo como base o desenho. Em seu processo de trabalho com essa linguagem, a fotografia foi empregada, desde os anos de 1980, como um meio para chegar à forma desejada.

Na série desenvolvida entre 1982 e 1983, os desenhos eram feitos sobre papel retangular e continham uma subdivisão. Na menor área do retângulo, em uma faixa lateral, havia a presença de detalhes de corpos masculinos sensuais e nus. Já no centro da área maior, composta por um fundo estampado com flores, o que se aproximava do aspecto de um tecido ou de um papel de parede, havia um objeto da cultura popular remetendo ao universo doméstico.
A aparência dos desenhos remete aos princípios de colagem e fotomontagem, nos quais convivem elementos díspares, heterogêneos, sem nexo direto entre si, mas que, associados, estabelecem uma familiaridade, uma analogia ocasional, como sugere a definição de montagem simbólica proposta por Jacques Rancière. Segundo o autor, "a maneira simbolista junta os elementos na forma do mistério [...] mistério é uma categoria estética elaborada por Mallarmé [...] é uma pequena máquina de teatro que fabrica analogia" (RANCIÈRE, 2011, p.79). Tal familiaridade, em analogia ocasional, é evidenciada no trabalho de Nicolaiewsky pela copresença entre a imagem da pele nua e os objetos de gosto popular, associando o corpo masculino sensual aos objetos kitsch, parecendo que o quadro estampado é um plano que encobre o resto, deixando uma fresta pela qual é possível espiar os homens, dessa forma, colocando-nos na posi- 
ção de voyeur. Trata-se de um ar doméstico, sugerindo espaços privados de um cotidiano nacional homoerótico. Em depoimento em vídeo, o artista revela que, no início dos anos de 1980, galerias, no Rio de Janeiro e em São Paulo, não concordaram em expor imagens com corpos de homens nus (NICOLAIEWSKY, 2011).

Nesses desenhos, em que o tema, também, é a memória do artista, a parte que expõe o corpo masculino é minuciosamente tratada e aproxima-se da estética hiper-realista, ao passo que a parte que contém os motivos de flores em repetição apresenta inscrições de palavras soltas, frases e desenhos como borboletas, cobras, nuvens, cavalos, sol, além de seu nome, juntamente com o objeto centralizado (um quadrinho com fotografias do artista quando bebê, o vaso de flores, o laçador, ou o São Jorge), segue uma estética de elaboração mais livre do traço, assim como o uso da mancha.

Ao escrever sobre a obra de Nicolaiewsky, apontando a junção de elementos heterogêneos sob o princípio da mestiçagem, Icleia Cattani definiu "Os lugares de mestiçagem, pois, não são criados pelos artista, mas sim, provocados pelos interstícios deixados entre as imagens." (CATTANI, In: FARIAS, 2004, p. 70).

Entre 1995 e 1997, ele desenvolveu a série Mistura fina, parte de seu trabalho de mestrado, ampliando a complexidade das misturas entre coisas de origens diversas, implicando elementos da memória pessoal e objetos da cultura. São obras que justapõem pinturas, desenhos, objetos e fotografias, numa operação de mestiçagem, como definido por Icléia Cattani. Mais tarde, esses mesmos elementos foram empregados em obras nas quais a captura de cenas de filmes é o ponto de partida e a impressão fotográfica, o ponto final. Nessas obras, Alfredo Nicolaiewsky apropria-se de imagens de filmes de diferentes diretores, converte-as em imagens fixas - retirando-as da continuidade do filme e tornando-as stills fotográficos -, seleciona grupos de imagens e justapõe-nas.

Em "Efeito filme: figuras, matérias e formas do cinema na fotografia", ao escrever sobre uma curadoria que realizou, Philippe Dubois comenta que visitar essa exposição equivaleria a ver um filme imaginário nas diversas salas. Efeito filme é, para o autor, uma questão de imagem, de dispositivo, tanto quanto de intelecção, de sensação e de emoção. Em tal exposição, o autor propunha a articulação entre cinema e fotografia em um único corpo figural "como o desdobramento híbrido de um mesmo conjunto figural de formas e de matérias”. (DUBOIS, 2004, p. 230, 258.) Este é o caso da obra "Três Histórias - Via Sacra”, de Alfredo Nicolaiewsky, apresentada, pela primeira vez, no Centro Cultural Mariantônia/USP, em 2007, na exposição individual intitulada "O Artista como Editor", que teve curadoria de Tadeu Chiarelli. É um conjunto de 36 fotografias composto por 12 tiras verticais, cada uma delas com três imagens fotográficas. São três sequências horizontais distintas, justapostas e intervaladas, medindo $150 \mathrm{~cm}$ de altura por $900 \mathrm{~cm}$ de largura.

O trabalho traz três narrativas simultâneas que se implicam e contaminam-se. A parte superior é uma sequência da vida de Jesus Cristo, da anunciação à ressurreição, as imagens são de um filme de 1905, de diretor desconhecido. Cada fotografia apresenta uma cena icônica da vida de Cristo, o filme em preto e branco foi
Figura 2 - Alfredo Nicolaiewsky, Três histórias, Via Sacra, 2007, Fotografia colada sobre poliestileno, $150 \times 950 \mathrm{~cm}$. Coleção MAC/USP doação Banco Itaú via AANAC. 
bilitando o surgimento de novos significados nas imagens ao serem lidas na vertical, painel a painel. (NICOLAIEWSKY, 2017, p. 27).

Se, por um lado, as sequências horizontais propõem um cruzamento de ritmos e tempos distintos, por outro, as relações entre as justaposições verticais são muito intrigantes, abrindo a possibilidade de indagações que beiram o nonsense: como cenas da vida de Cristo que passam por situações de suspense e chegam a um olhar romântico da personagem da linha de baixo? Ou, ainda, como o sorriso romântico desta mulher perpassa cenas de suspense chegando a imagens da história de Cristo? Vê-se aqui a montagem caótica, a montagem por choques, uma montagem dialética (RANCIÈRE, 2011, p. 77).

O processo de produção envolveu assistir a filmes e escolher determinadas capturas de imagens no computador (isso consiste na visualização do material e no acionamento de uma pausa para a retirada de um frame, um still eletrônico) e, depois, classificar e guardar os arquivos, diferindo em método da série que realizou durante seu doutorado, entre 1998 e 2001, quando a captura de imagens de filmes era feita usando a fotografia analógica. Nicolaievsky costumava retirar os filmes em locadoras, assistiathes, escolhia as cenas a fotografar, colocava o videocassete em pausa e, com a câmera em mãos, capturava a cena

emitida pelo aparelho de televisão. As imagens resultantes, na maior parte dípticos, continham, então, uma textura muito característica - os dots do aparelho e seus múltiplos pontos de luz capturados pelo filme, criando uma textura na imagem. Após serem reveladas, elas eram digitalizadas e impressas em lona vinílica esticada sobre bastidores e, posteriormente, sobre papel fotográfico colado sobre MDF.

\section{"A Ira de Deus"}

Em 2015, Alfredo Nicolaiewsky foi para Portugal realizar seu Pós-Doutoramento na Universidade de Lisboa. Para seu projeto, planejou dar continuidade ao mesmo princípio estrutural empregado em "Três histórias: Via Sacra”, uma justaposição de três sequências temporais oriundas de filmes distintos, porém em uma forma espacial mais ampla e com um tema diferente. Chegando lá, a temática escoIhida foi o terremoto de 1755, em Lisboa. (NICOLAIEWSKY, 2017, p. 35 -36).

A dificuldade de encontrar locadoras de filmes e DVDs fez com que o artista readaptasse seu método de trabalho, para tanto, fez pesquisas na internet. Assim, diante dessas circunstâncias específicas da vida em Lisboa, no ano de 2015, "A Ira de Deus" teve como fonte de captura o YouTube, ou seja, estruturou-se como um processo de navegação no espaço virtual da internet. Quando iniciou as buscas, o artista deparou-se com um pequeno problema que redirecionou suas escolhas de cenas. Diferentemente do imaginado, os filmes que reconstituem o episódio não transmitiam a grandeza da catástrofe que ele queria encontrar.

O tema escolhido apresentou algumas dificuldades quanto à escolha de imagens. As reconstituições fílmicas do Terremoto de 1755, não transmitiam, quando transformadas em imagens fixas, a grandeza da catástrofe. [...] Porém, como estava trabalhando a partir de imagens captadas no YouTube, começaram a aparecer vídeos jornalísticos e ficcionais de tragédias contemporâneas semelhantes, como outros terremotos, o tsunami no Japão (2011) ou o incêndio no bairro Chiado - Lisboa (1988). (NICOLAIEWSKY, 2017, p. 36)

O tríptico, propriamente dito, é constituído por imagens do terremoto, do maremoto e do incêndio. São nove sequências fotográficas formadas 


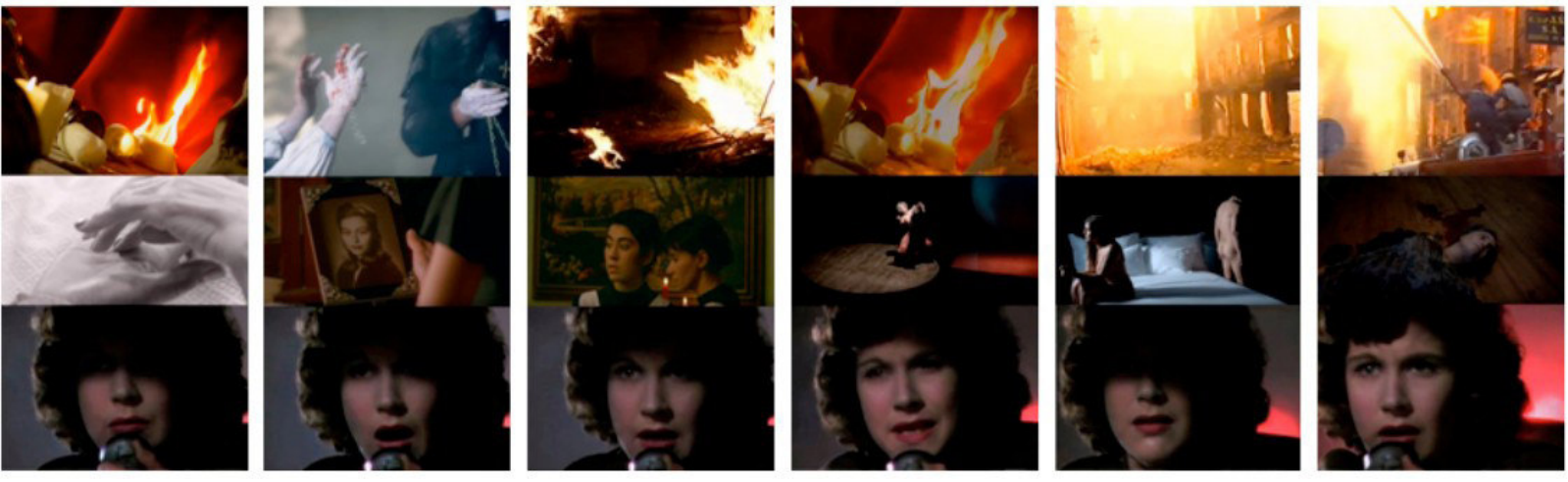

sequência de uma despedida, em plano médio, vista pela perspectiva de um menino.

Na parte 3: O incêndio, há, na linha superior, imagens de incêndios; alguns ocorreram em Lisboa, 1988, e destruíram muitos prédios no bairro Chiado. Na parte central, a sequência é toda noturna, a primeira fotografia mostra uma mão feminina, em preto e branco e em close, pegando um objeto transparente, na seguinte, outra mão feminina segura um retrato. Na sequência são mostradas duas jovens que conversam, uma mulher sentada em uma cadeira em um palco, um casal no quarto - ela sentada à beira da cama, ele de costas em pé -, o rosto de uma mulher no chão e, por fim, uma cena em um outro quarto, sob uma luz âmbar, onde um homem está de costas em pé. E, na base, novamente um rosto de mulher em close que, pela presença do microfone, podemos pensar em uma cena em que algum jornalista transmite uma notícia.

O que é narrado? Quando aconteceu? Não há um sentido único, há uma ampliação do espaço fotográfico e um multidirecionamento do tempo, pois, na internet (de onde foram capturados os stills), o acesso permitido pelas plataformas faz convergir imagens de outras épocas, que, por sua vez, contam histórias de outras tantas. O tríptico produzido trata de uma ficção distópica, uma tragédia na qual as forças da natureza movimentam destruição, rupturas e afastamentos sob o signo da montagem transmidiática ou montagem por reconversões fílmicas, que é como poderiam ser nomeados esses transportes de um meio a outro, do filme passando pela imagem eletrônica, sua flutuação e reconversão em imagem estática, resultando numa sequência de colagens de

Estudos de Tadeu Chiarelli revelaram a existência de uma produção de fotomontagens com características surrealistas em obras de Alberto da Veiga Guignard, Jorge de Lima e Athos Bulcão: "Nelas será vista a mesma inquietante procura de criação de espaços oníricos, lugares improváveis onde figuras estranhas colocam-se como personagens de alegorias quase impossíveis de serem decodificadas objetivamente." (CHIARELLI, 2003, p. 73). Assim como nas obras, da década de 1940, desses artistas brasileiros, as fotomontagens surrealistas trazem o mistério pela sugestão de existência de determinada continuidade espacial, do reconhecimento de certos objetos deslocados de seu contexto original, podemos vê-las empregando o princípio de analogia ocasional que transmite uma familiaridade - a montagem simbólica definida por Rancière, citada no início do texto.

O trabalho de Nicolaiewsky está longe de ser uma fotomontagem como a dos surrealistas, dadaístas ou construtivistas, por isso, outras referências são importantes, como o uso da sequência na fotografia - as folhas de contato de filmes negativos, as fotografias panorâmicas com múltiplas obtenções, as sequências fotográficas do período da Arte Conceitual, destacando as obras de Andy Warhol, Douglas Huebler, Helena Almeida, Paulo Bruscky e Carlos Pasquetti. Cabe mencionar John Baldessari, Keith Arnatt, Allan Sekula, Duane Michals e Sophie Calle, artistas que trabalham com vários cenas, uma montagem fotográfica.
Figura 6 - Alfredo Nicolaiewsky, A Ira de Deus - parte 3: 0 incêndio. Imagens digitais sobre papel, $100 \times 460 \mathrm{~cm}$. 2015-16. 
meios, não apenas a fotografia, e, em especial, os artistas citados por Nicolaiewsky - Eric Rondepierre, Rosangela Rennó, Victor Burgin e Vera Chaves Barcellos no artigo "De película: narrativas fotográficas de Vera Chaves Barcellos”(NICOLAIEWSKY, 2012, p. 316-320), pois, além de em algumas de suas obras tratarem da ideia de sequência e narrativa, também, lidam com a apropriação de cenas por meio da captura fotográfica de arquivos, filmes, vídeos ou programas de televisão.

Nas últimas décadas, as possibilidades oferecidas pela indústria de impressão digital alargaram as perspectivas de exploração da espacialização da fotografia - hoje, é possível usar muitos materiais além do papel fotográfico para impressão de imagens: tecidos, superfícies rígidas lisas ou porosas, transparentes ou opacas, objetos e gigantografias. A ideia de narrativas paralelas que se cruzam já habita nosso imaginário, está inscrita em nossa vivência no dia a dia. A música, a literatura e o cinema não cessam de nos oferecer imersões em temporalidades polifônicas.

Maria do Carmo Nino, escrevendo sobre as narrativas sequenciais, afirma "a sequência gera um tempo interno que tem a ver essencialmente com a sua recepção por parte do leitor [...]" (NINO, 2007, p. 142), ela frisa o limite intrínseco do recorte fotográfico e, nos intervalos entre uma imagem e outra, provoca uma suspensão, possibilitando-nos, como sugere, experienciar um tempo interno como apreciadores da obra.

Interessa, ainda, pensar que é no espaço entre dois fotogramas, nesse intervalo que se produz o princípio da montagem, que a sequência de cenas se abre para o observador, numa estrutura que pode se aproximar, conceitualmente, do Quase Cinema proposto por Oiticica, à medida que esse espaço entre dois fotogramas, entre dois quadros, entre duas molduras, é simulta- neamente uma circunscrição e uma abertura, uma direção de olhar e um convite à percepção.

Nicolaiewsky não está explorando as espacializações internas da imagem, como acontecia no início do século XX, ou discutindo verdades. Sua montagem de fotografias, propiciada pelo emprego da impressão digital, decorre antes da herança deixada pela seriação minimalista que impele o observador de mover seu olhar para além dos limites de um quadro. Porém a seriação nessas obras não significa neutralidade, tautologia ou repetição, como acontecia nas obras do minimalismo. Em "A Ira de Deus", a seriação indica sequência, faz referência à continuidade, intenciona criar uma história, uma fábula. Quer provocar o observador a animar a obra.

Em "A Ira de Deus", Nicolaiewsky apresenta o resultado de um processo híbrido, que encadeia imagens moventes e imagens estáticas, e é perpassado pelo sistema eletrônico em diferentes etapas - desestabilizando circunscrições classificatórias em meios específicos. Nessas sequências, empregando a lógica associativa da justaposição, heterogêneos são aproximados, acionando, simultaneamente, montagem simbólica e montagem dialética. Assim como nos seus trabalhos anteriores, a apropriação de imagens de filmes e a justaposição continuaram sendo as operações-chave do seu processo de trabalho. Agora, com a montagem ampliada para um tríptico, há uma estrutura panorâmica extensa, quem a vê precisa caminhar para passar pelas diferentes telas que sugerem um mosaico de referências situado entre a fotografia e o cinema disponível na internet.

Alfredo Nicolaiewsky está construindo narrativas fotográficas que se superpõem, nessas obras, uma simultaneidade é exposta, transmitindo um cruzamento de histórias pelo qual se observam uma condensação de sentidos e 
muitas contrações e intervalos temporais. Esses intervalos, articulados sob a égide das elipses existentes entre as imagens nas sequências horizontais, os saltos temáticos presentes nas sequências verticais e suas justaposições constituem uma narrativa ramificada e multitemporal. É uma gramática visual única, ancorada na transmigração eletrônica das imagens, que convida o observador a animar a obra e a experienciar certo efeito filme remontando "A Ira de Deus”.

\section{Referências}

CATTANI, Icleia Borsa (Org.). Mestiçagens na arte contemporânea. Porto Alegre: Editora da UFRGS, 2007.

DUBOIS, Philippe. Efeito filme: figuras, matérias e formas do cinema na fotografia, In: SANTOS, Alexandre; DOS SANTOS, Maria Ivone (Org.). A Fotografia nos processos artísticos contemporâneos. Porto Alegre: UFRGS Editora, 2004. p.230-258.

EISENSTEIN, Serguei. Montage is conflict/1929/. In: THE CINEMATIC, Documents of Contemporary Art. Londres: Whitechapel Gallery, 2007. p. 30-32.

FARIAS, Agnaldo (Org). Icleia Cattani. Rio de Janeiro: FUNARTE, 2004. (Coleção Pensamento Crítico).

NICOLAIEWSKY, Alfredo. Depoimento em Documentário - Pintura, da matéria à representação - Alfredo Nicolaiewsky - Parte 11. Fundação Vera Chaves Barcellos, 2011. Disponível em: <https://www.youtube.com/watch?v=UPiRlyGZZ74>. Acesso em: 10 se. 2019.

Relatório final Pós-Doutoramento. Lisboa: Faculdade de Belas Artes da Universidade de Lisboa, 2016.

De película: narrativas fotográficas de Vera Chaves Barcellos. Lisboa: Universidade de
Lisboa, Congresso CSO. Revista Estúdio, 2012. v. 3, n. 5, p. 316-320. ISSN 1647-6158.

Alfredo Nicolaiewsky e a Ira de Deus:

suas prequelas e sequelas. Porto Alegre: UFRGS Editora, 2017.

NINO, Maria do Carmo. Narrativas sequenciais na fotografia. Graphos, v. 9, n.1, jan./jul. 2007.

RANCIÈRE, Jaques. 0 destino das imagens. Lisboa: Orfeu Negro, 2011.

\section{Elaine Tedesco}

Doutora em Poéticas Visuais pela Universidade Federal do Rio Grande do Sul (2009). Artista plástica com produção em fotografia, instalação e videoperformance. É professora adjunto no Instituto de Artes da Universidade Federal do Rio Grande do Sul, atua junto ao Departamento de Artes Visuais na área de fotografia e no Programa de Pós-Graduação em Artes Visuais. 